Contents List available at RAZI Publishing

Acta Scientifica Malaysia (ASM)

Journal Homepage: http://www.razipublishing.com/journals/acta-scientificamalaysia-asm/archives/

https://doi.org/10.26480/asm.01.2017.04.07

\title{
BLOOD LEAD CONCENTRATION AND WORKING MEMORY ABILITY ON MALAY PRIMARY SCHOOL CHILDREN IN URBAN AND RURAL AREA, MALACCA
}

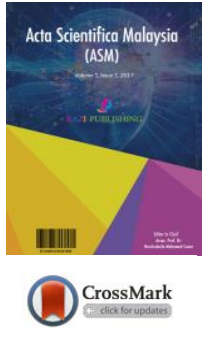

\author{
Shamsul Bahari Shamsudin' , 'Adilah Marzuki ${ }^{2}$, Mohammad Saffree Jeffre ${ }^{3}$ and Khamisah Awang Lukman ${ }^{3}$ \\ ${ }^{1}$ Centre of Occupational Safety and Health, Universiti Malaysia Sabah, Jalan UMS 88400, Kota Kinabalu, Sabah \\ ${ }^{2}$ Department of Community Health, Faculty of Medical and Health Sciences, Universiti Putra \\ Malaysia, 43400 UPM Serdang, Selangor \\ ${ }^{3}$ Faculty of Medicine and Health Sciences, Universiti Malaysia Sabah, 88400 Kota Kinabalu, Sabah, Malaysia
}

This is an open access article distributed under the Creative Commons Attribution License, which permits unrestricted use, distribution, and reproduction in any medium, provided the original work is properly cited.

\section{ARTICLE DETAILS}

Article history:

Received 12 August 2016 Accepted 12 December 2016 Available online 20 January 2017

Keywords:

Blood lead, Working Memory Ability, Urban and Rural, Children
ABSTRACT

The most lead concentrations in the environment come from human activities such as burning fossil fuels, mining and manufacturing. Once lead enters into environment, it does not break down, but lead compounds were changed by sunlight, air and water. The main target for lead toxicity is nervous system. A child's mental and physical growth can be affected even at low levels of exposure. Objective of this study was to determine the relationship between blood lead concentration and working memory ability among primary school children in urban and rural area, Melaka. The final number of 111 respondents participates in this study which represents 37 from urban area and 74 from rural area. The biological indicator for lead exposure was blood sample. WMI consist of Digit Span as a subtest which comprise of Digit Span Forward (auditory short-term memory) and Digit Span Backward (auditory working memory). The mean of blood lead concentration for urban children was $8.51 \pm 3.61 \mu \mathrm{g} / \mathrm{dL}$ and rural children were $6.86 \pm 4.63 \mu \mathrm{g} / \mathrm{dL}$. There was significant difference of blood lead concentration between urban and rural children ( $\mathrm{t}=2.061, \mathrm{p}=0.042)$. Result showed the mean of WMI score for urban children was $82.03 \pm 12.55$ and rural children the mean score of WMI was 87.30 \pm 13.88 . There was significant different of WMI score between urban and rural children $(\mathrm{t}=-2.012, \mathrm{p}=0.048)$. Result showed there was significant inversely correlation of WMI score with blood lead concentration among urban $(\mathrm{r}=-0.417, \mathrm{p}=0.010)$ and rural $(\mathrm{r}=-0.369, \mathrm{p}=0.001)$ children, and there was no association of socio-economic variables with WMI score. This study had made the conclusions; there was significant difference of blood lead concentration among urban and rural children. Urban children state high concentration rather than rural children. There was a significant difference of working memory ability among urban and rural children. Urban children showed lower score compared to rural children. There was inversely significant correlation between blood lead concentration and working memory ability among primary school children in urban and rural area, Melaka.

\section{INTRODUCTION}

Lead is a highly toxic metal which is naturally occurring bluish-gray metal found in small amounts of the earth's crust at about $15-20 \mathrm{mg} / \mathrm{kg}$. The characteristics of lead are very soft, highly malleable, ductile and relatively poor conductor of electricity. Besides that, it is also very resistant to corrosion but tarnishes upon exposure to air. Native lead is rare in nature. Currently lead is usually found in ore with zinc, silver and copper and it was extracted together with these metals. The main lead mineral in galena $(\mathrm{PbS})$ and there are also deposits of cerrussite $\left(\mathrm{PbSO}_{4}\right)$ and anglesite $\left(\mathrm{PbCO}_{3}\right)$ which are mined (ATSDR, 2011). However, most lead concentrations in the environment come from human activities such as burning fossil fuels, mining and manufacturing. Once lead enters into environment, it does not break down, but lead compounds were changed by sunlight, air and water. It may travel long distance before settling to the ground if the lead particles are very small. In air, most lead is in form of fine particle with diameter less than $1 \mu \mathrm{m}$ (Agius, 2012). Estimation on lead that emitted into the atmosphere is about $0.33 \times 10^{9} \mathrm{~kg}$ (WHO, 2015). Once lead falls onto soil, it sticks strongly to the soil particles and remains in the upper layer of soil. Movement of lead from soil into groundwater will depend on the type of lead compound, and physical and chemical characteristics of the soil (ATSDR, 2011).

Lead poisoning occurs when lead builds up in the human body that enters through routes of exposure which are ingestion, inhalation and dermal contact. The adverse health effects of lead are same whether it enters the body through breathing or swallowing. Once lead absorb in the body, it will circulate through blood circulatory system and distribute to organs and soft tissues. For adults and children, the main target for lead toxicity is nervous system. Long term exposure of lead to adults at work has resulted in decreased performance in some tests that measure nervous system functions (Agius, 2012). A child's mental and physical growth can be affected even at low levels of exposure (ATSDR, 2011). Most findings reported that blood lead has an inverse relationship with mental development and there is a reduction in intellectual quotient (IQ) when blood lead concentration exceeds $10 \mu \mathrm{g} / \mathrm{dL}$ (CDC, 2014). At high levels of exposure, lead can severely damage the brain in adults and children and ultimately cause death.

Children exposed to lead all through their live are more vulnerable to lead poisoning than adults. They can be exposed to lead in the womb if their mothers have lead in their bodies (Ashley-Martin et al., 2015; Thomas et al., 2015; Shamsul et al., 2003). Babies can swallow lead when they breast feed, eat foods and drink water that contains lead. In addition, babies and children can swallow and breathe lead in dirt, dust, or sand while they play on the floor or ground. Children are more sensitive to the health effects of lead than adults especially on the nervous system. No safe blood lead level in children has been determined (CDC, 2014; ATSDR, 2011). Childhood lead poisoning continue to be a major public health problem for certain groups of children, specifically low income, urban (Kordas et al., 2015; Hashim et al., 2000; Shamsul et al., 2003), suffer from abuse and neglect, live in rural mining communities (Ona et al., 2006), and in developing countries (Zailina et al., 2008). In Malaysia, previous study stated that lead concentration in air at city or urban area was five times greater compared to rural area (Hashim et al., 2000). This was because most of the sources of lead in air at urban area came from high emission from exhaust mobile due to high traffic density (Zailina et al., 2008), 
urbanization development and increase of human activities. Objective of this study was to determine the relationship between blood lead concentration and working memory ability among primary school children in urban and rural area, Melaka.

\section{Materials and methods}

This cross-sectional study was conducted on February to June 2015 at two different areas which represented an urban and rural area in Melaka. The urban area located at Padang Temu, Banda Hilir and the main activities here were mainly tourism and industria manufacturing. Meanwhile, Kuala Linggi, Kuala Sungai Baru represented the rural area and it is fishing villages near to the Straits of Malacca. These two areas was selected base on the factors of location, economic activities and environment factors. Selection of schoolbase respondents by stratified random sampling. The sampling frame in this study was the name list of standard 4 and 5 students provided by the class teachers in both schools. The sampling unit was a student of standard 4 and 5 whom fulfilled the selection criteria. The inclusive criteria of study sample unit that must be fulfilled were Malay ethnic group, aged 10 to 11 years old and local residents of study location not less than 10 years. Any children who were diagnosed with any type of mental illnesses or brain injury were excluded from this study. The final number of 111 respondents participates in this study which represents 37 from urban area and 74 from rural area. The samples selection selected among those school children who were voluntary and get consent from parent to be respondents of this study.

\section{Questionnaire}

A set of questionnaire was used to gather the demographic and socioeconomic information of each respondent. The questionnaire comprised of several parts; socioeconomic status, background information and health status of the respondents. The questionnaire was pretested to ensure the questions were suitable and understandable. The research procedures and process was explained to the respondents and parents before they get involved in this study.

\section{Blood lead}

The biological indicator for lead exposure was blood sample. The blood sample collection taken from capillary was conducted from each of the respondents using finger prick method by a registered medical assistant. The hygienic and strict cleaning procedure was practiced. The materials used are antibacterial soap, distilled water, alcohol swab, disposable glove, disposable lancet, capillary tube 100 $\mu \mathrm{L}$, applicator and Becton Dickinson pink-top microtainer tube contain of $500 \mu \mathrm{L}$ matrix modifier. Blood sample were stored in a cool box and the temperature is maintain at $2^{\circ} \mathrm{C}$ until $8^{\circ} \mathrm{C}$. The blood sample was ready for blood analysis. Blood lead concentration was analyzed with Graphite Furnace Atomic Absorption Spectrophotometer (GFAAS) model Perkin Elmer AAnalyst 600 with WinLab 32 Software Version 6.5. The method and procedure to operate the GFAAS was based on the manual provided by manufacturer and incorporated with standard method. The temperature of pyrolisis and atomization were $850^{\circ} \mathrm{C}$ and $1600^{\circ} \mathrm{C}$ respectively.

\section{Working Memory Index (WMI)}

The Wechsler Intelligence Scale for Children version IV (WISC-IV) consists of four indexes which comprise seven subtests. The indexes are called Verbal Comprehension Index (VCI), Perceptual Reasoning Index (PRI), Working Memory Index (WMI) and Processing Speed Index (PSI). In this study, only WMI was involved. WMI requires working memory processes to manipulate orally presented verba sequences or to simply recall orally presented sequential information. WMI consist of Digit Span as a subtest which comprise of Digit Span Forward (auditory short-term memory) and Digit Span Backward (auditory working memory).

\section{Ethical Clearance}

The methodology of this study was approved by Ethics Committee of Faculty of Medicine and Health Science, Universiti Putra Malaysia. Written permission was obtained from the Ministry of Education, Malaysia, Department of State Education, Melaka, and selected schools. Parents who agreed of the involvement of their children in this study had signed the consent letter and understood that they were permitted to withdraw from the study anytime as they wish.
Furthermore, the consent form was aimed to inform them that all the effects that they will get from the study were the responsibility of the researcher. Individual data are confidential. The reports of the study will be sent to Ministry of Education and selected schools.

\section{Results}

The total sample size after exclusion of those who did not met the inclusive criteria were 111 respondents from which 37 (33.3\%) of them were urban children and other $74(66.7 \%)$ were rural children. The mean and standard deviation age for the study population was $10.69 \pm 0.46$ years old with the minimum age was 10 and maximum age was 11 . From the study population, the total of male respondents were $58(52.3 \%)$ while other $53(47.7 \%)$ were female.

The mean of blood lead concentration for urban children was $8.51 \pm 3.61 \mu \mathrm{g} / \mathrm{dL}$, the maximum value was $19.36 \mu \mathrm{g} / \mathrm{dL}$ and the minimum value was $3.32 \mu \mathrm{g} / \mathrm{dL}$ (Figure 1). Meanwhile, the mean blood lead concentration of rural children was $6.86 \pm 4.63 \mu \mathrm{g} / \mathrm{dL}$ and the maximum value was $22.08 \mu \mathrm{g} / \mathrm{dL}$ while minimum value was $1.89 \mu \mathrm{g} / \mathrm{dL}$ (Figure 2). That was $27 \%$ of urban children and $20.3 \%$ of rural children were exceeded $10 \mu \mathrm{g} / \mathrm{dL}$. The statistical test of difference indicate that there was significant difference of blood lead concentration between urban and rural children $(t=2.061, p=0.042)$.

Result showed the mean of WMI score for urban children was $82.03 \pm 12.55$ with maximum and minimum score were 115 and 55 (Figure 3). Meanwhile, for rural children the mean score of WMI was $87.30 \pm 13.88$ with minimum and maximum value are 15 and 125 respectively (Figure 4 ). Table 1 showed $91.9 \%$ of urban children and $83.8 \%$ of rural children were in the category below the average level of WMI score.

Table 2 showed the t-test analysis of WMI parameters between this study groups. There was significant different of WMI score $(\mathrm{t}=-2.012$ $\mathrm{p}=0.048$ ). The result also showed that there was no significant difference of variable Digit Span Forward $(t=-1.807, p=0.075)$ but there was significant different of Digit Span Backward $(\mathrm{t}=-2.162$, $\mathrm{p}=0.034$ ). Besides that, the mean and standard deviation of Digit Span Forward was lower for urban children were $5.92 \pm 1.82$ compare to the mean obtained from rural children were $6.58 \pm 1.83$. There was same condition apply to Digit Span Backward of urban children were $4.00 \pm 1.58$ respectively lover compare to rural children $4.70 \pm 1.68$.

Table 3 showed there was significant inversely correlation of WMI score with blood lead concentration among urban $(\mathrm{r}=-0.417$ $\mathrm{p}=0.010)$ and rural $(\mathrm{r}=-0.369, \mathrm{p}=0.001)$ children. Table 4 showed there was no association of socio-economic variables with WMI score among urban and rural children.

\section{Discussions}

Lead is an element with unknown physiologic function in humans but adversely affects a variety of fundamental biochemical process. Lead poisoning is a substantial problem in developing countries (Zailina et al., 2008). The permissible value of blood lead concentrations for children was below $10 \mu \mathrm{g} / \mathrm{dL}$ (CDC, 2014). Majority of the children reported a normal or lower than the allowable standard blood lead concentrations. This study found that 10 children in urban $(27 \%)$ and 15 from rural (20.3\%) have blood lead concentrations higher than $10 \mu \mathrm{g} / \mathrm{dL}$

The Centers for Disease Control has defined an elevated blood lead level in children as more than $10 \mu \mathrm{g} / \mathrm{dL}$ on the basis of neurologic toxicity (CDC, 2014). This value is extremely important because policy makers and public health officials generally have acted to remove sources of lead only after the Centers of Disease Control level of concern had been exceeded. Although the CDC's current definition is $10 \mu \mathrm{g} / \mathrm{dL}$, lead levels below

$10 \mu \mathrm{g} / \mathrm{dL}$ have recently been associated with neurocognitive deficits in children (Bellinger, 2013; Even et al., 2015) and no "safe" level has yet been established (Shamsul et al., 2003).

Blood lead concentration is the most widely used and considered to be the most reliable biomarker for general clinical use and public health surveillance. Currently, blood lead measurement is the screening test of choice to identify children with elevated blood lead level. In children, blood lead concentration between $10 \mu \mathrm{g} / \mathrm{dL}$ and 
$14 \mu \mathrm{g} / \mathrm{dL}$ should trigger community-wide childhood lead poisoning prevention activities (CDC, 2014). Since the elimination half-time of lead in blood is approximately 30 days, blood lead generally reflect relatively recent exposure and cannot be used to distinguish between low-level intermediate or chronic exposure and high level acute exposure. A blood lead level will tell if a child has been exposed to lead in the last 3 to 4 months.

The t-test has been conducted to know the difference of blood lead concentration between both groups of children. From the result of the $\mathrm{t}$-test, it showed that there was significant difference of blood lead concentration ( $\mathrm{t}=2.061, \mathrm{p}=0.042)$. Urban children had higher blood lead concentration compared to rural children caused by several reasons. During this study was conducted, Sekolah Kebangsaan Padang Temu was in construction to build new academic building and indirectly, children will inhaled lead-containing dust. Besides that this was due to high traffic density that increases the lead emission in air and soil. From previous study, it showed within 25 meters of major roadways, lead concentrations in soil as high as 2,000 part per million (ppm) are found. These concentrations fall of exponentially with distance. In urban soils, the lead found is a mixture of powdered paint and atmospheric fallout of lead particles (Mazumdar et al., 2011).

This result was similar with previous study that reported there was a significant different between urban and rural area in Malaysia (Zailina et al., 2008). Data on respirable lead and blood lead of 346 school children were obtained from Kuala Lumpur (urban), Kemaman (semi-urban) and Setiu (rural). Respirable lead and blood lead were highest for Kuala Lumpur $\left(95 \mathrm{ng} / \mathrm{m}^{3}\right.$ and $\left.5.26 \mu \mathrm{g} / \mathrm{dL}\right)$ followed by Kemaman $\left(27 \mathrm{ng} / \mathrm{m}^{3}\right.$ and $\left.2.81 \mu \mathrm{g} / \mathrm{dL}\right)$ and Setiu $\left(15 \mathrm{ng} / \mathrm{m}^{3}\right.$ and $2.49 \mu \mathrm{g} / \mathrm{dL}$ ). The differences were statistically significant. Regression analysis shows that urban children are at higher risk of exhibiting excessive blood lead levels. Kuala Lumpur's school children have a 25 times greater risk of having excessive blood lead levels when compared to Kemaman's and Setiu's school children. Other study also states that mean blood lead concentration was higher in the urban area $(8.3 \mu \mathrm{g} / \mathrm{dL})$ than in suburban area $(6.9 \mu \mathrm{g} / \mathrm{dL})$ (Mazumdar et al., 2011).

The Working Memory Index (WMI) was derived from the Digit Span subtest. This subtest basically measured the attention and concentration of the respondent. From the results of this study, it showed that most of the urban children (91.9\%) and rural children (83.8\%) have WMI score lower than average of WMI score which is $100 \pm 15$. The finding also showed that urban children $(82.03 \pm 12.55)$ have lower score compared to rural children $(87.30 \pm 13.88)$ and had significant different. This was cause by higher blood lead concentration of urban children than the children in rural area. In Digit Span subtest, the respondent was measured the degree of their free from distraction state. Based from the results, the urban children seemed to be easier to be distracted and eventually not performed well in this subtest.

One of the serious outcomes of lead exposure is a decline in cognitive functioning (memory, attention, language, concept formation, problem solving, executive and visuospatial functions) which also has an impact on school performance (Surkan et al., 2007). Lead toxicity has detrimental effects to the nervous system and the brain, thus impairing the memory abilities of a person. Higher blood lead levels were associated not just with lower scores on tests of neuropsychological domains, but also with lower scores on tests of academic achievement (Surkan et al., 2007)

Previous study reported the same result with this study which mean cognitive score (102.55) of the children from the industrial area was significantly higher than that of the urban children $(p<0.001)$. The McCarthy Scales of Children Abilities (MSCA) test showed that the mean General Cognitive Score or the IQ of the children in the industrial estate $(102.55 \pm 12.41)$ was significantly higher than the children in the urban area $(95.09 \pm 13.98)$ (Zailina et al., 2008).

From the statistical analysis, there was inversely significant association between blood lead concentration and working memory ability among urban and rural children. It means that when the blood lead concentration was high, the working memory ability will be low. This finding was consistent with previous studies. Zailina et al., (2008) showed there was a significant inverse relationship between blood lead concentrations and cognitive scores for all the children studied in urban and industrialized area. Besides that, another literature study reported that blood lead of about $4.30 \mu \mathrm{g} / \mathrm{dL}$ could affect the cognitive development of children (Zailina et al., 1998) Other researchers also reported that the cognitive score

(IQ) of children were affected by blood lead concentrations higher than $10 \mu \mathrm{g} / \mathrm{dL}$

Numerous studies indicate that blood lead concentrations above $10 \mu \mathrm{g} / \mathrm{dL}(0.483 \mu \mathrm{mol} / \mathrm{L})$ are associated with adverse outcome on measures of intellectual functioning and socialbehavioral conduct (Shamsul at al., 2003). Besides that, the estimated IQ loss was 4.6 points for each increase in the blood lead concentration of $10 \mu \mathrm{g} / \mathrm{dL}$. For every $1 \mu \mathrm{g} / \mathrm{dL}$ increase in blood lead concentration, there was a 0.7 point decrement in mean arithmetic scores, an approximately point decrement in mean reading scores, a 0.1 point decrement in mean scores on a measure of nonverbal reasoning, and a 0.5 point decrement in mean scores on a measure of short-term memory (Shamsul et al., 2003).

Previous study also showed there was inversely correlated between blood lead level and working memory ability. Blood lead levels of 5-10 $\mu \mathrm{g} / \mathrm{dL}$ were associated with decreased attention and working memory. Overall, the analyses support prior research that children's blood levels less than $10 \mu \mathrm{g} / \mathrm{dL}$ are related to compromised cognition and highlight that these may especially be related to academic achievement (Zailina et al., 2002). Other previous study indicated that there was a significant association between lead exposure and neurobehavioral tests, such as simple reaction and digit span which reflect attention and short-term memory. In particular, attention and memory appeared at very low level of blood lead (Hashim et al., 2000).

Mostafa et al., (2009) stated that children with cognitive dysfunction had higher blood lead levels than those with normal cognitive function. Poor scholastic achievement was reported in 33\% of the children, of whom $87.9 \%$ had cognitive dysfunction and $90.9 \%$ had blood lead levels more than $10 \mu \mathrm{g} / \mathrm{dL}$. The frequency of poor scholastic achievement was significantly higher in children with cognitive dysfunction than those who were without. Similarly, the frequency of poor scholastic achievement was significantly higher in children with blood lead levels more than $10 \mu \mathrm{g} / \mathrm{dL}$ than those with levels less than $10 \mu \mathrm{g} / \mathrm{dL}$. Blood lead level more than $10 \mu \mathrm{g} / \mathrm{dL}$ was the most significant independent predictor of cognitive dysfunction followed by the degree of lead exposure in a logistic regression analysis in the children. There was a consistent finding in this study that deficits were found on only four subtests of the verbal and performance IQ (digit span, arithmetic, digit symbol and block design). These tests are used in a clinical setting to show abilities in working memory attention (digit span and arithmetic), processing speed (digit symbol) and perceptual reasoning (block design).

Other factors such as age, household income, parent's education, body mass index, preschool education, number of sibling and duration of outdoor activities did not have significant association with working memory ability. In short, working memory ability among urban and rural children was associated with blood lead concentration even after considered other factors.

\section{Conclusion}

This study had made the conclusions; there was significant difference of blood lead concentration among urban and rural children. Urban children state high concentration rather than rural children. There was a significant difference of working memory ability among urban and rural children. Urban children showed lower score compared to rural children. There was inversely significant correlation between blood lead concentration and working memory ability among primary school children in urban and rural area, Melaka.

\section{References}

[1] Agius R. 2012. Lead in the environment and health. http://www.agius.com/hew/resource/lead.htm (visited 24/12/2015)

[2] Ashley-Martin J, Dodds L, Arbuckle TE, Ettinger AS, Shapiro GD, Fisher M, Taback S, Bouchard MF, Monnier P, Dallaire R, Fraser WD. 2015. Maternal blood metal levels and fetal markers of metabolic function. Environ Res. 2015 Jan;136:27-34. 
2011. Lead.

http://www.atsdr.cdc.gov/substances/toxsubstance.asp?toxid=22 (visited 22/02/2016)

[4] Bellinger DC. 2013. Prenatal Exposures to Environmental Chemicals and Children's Neurodevelopment: An Update. Saf Health Work. 2013 Mar; 4(1):1-11

[5] CDC - Centers for Disease Control and Prevention. 2014. Blood Lead Levels in Children http://www.cdc.gov/nceh/lead/ACCLPP/blood_lead_levels.htm (visited 20/02/2016)

[6] Evens A, Hryhorczuk D, Lanphear BP, Rankin KM, Lewis DA, Forst L, Rosenberg D. 2015. The impact of low-level lead toxicity on school performance among children in the Chicago Public Schools: a populationbased retrospective cohort study. Environ Health. 2015 Apr 7;14:21

[7] Hashim JH, Hashim Z, Omar A, Shamsudin SB. 2000. Blood lead levels of urban and rural Malaysian primary school children. Asia Pac J Public Health. 2000;12(2):65-70.

[8] Kordas K, Ardoino G, Coffman DL, Queirolo EI, Ciccariello D, Mañay N, Ettinger AS. 2015. Patterns of exposure to multiple metals and associations with neurodevelopment of preschool children from Montevideo, Uruguay. J Environ Public Health. 2015;2015:493471

[9] Mazumdar M, Bellinger DC, Gregas M, Abanilla K, Bacic J, Needleman HL. 2011. Lowlevel environmental lead exposure in childhood and adult intellectual function: a follow-up study. Environ Health. $2011 \mathrm{Mar}$ $30 ; 10: 24$

[10] Mostafa GA, El-Shahawi HH, Mokhtar A. 2009. Blood lead levels in Egyptian children from high and low lead-polluted areas: impact on cognitive function. Acta Neurol Scand. 2009 Jul;120(1):30-7

[11] Ona LF, Alberto AM, Prudente JA, Sigua GC. 2006. Levels of lead in urban soils from selected cities in a central region of the Philippines. Environ Sci Pollut Res Int. 2006 May;13(3):177-83.

[12] Shamsul B.S, Jamal H.H. , Nik Nasri N.I. and Abdul Rahman A.J. 2003. Blood lead concentration during pregnancy and the health implication to the mothers and their babies. Epidemiology, 14(5)Suppl.2003 Surkan PJ, Zhang A, Trachtenberg F, Daniel DB, McKinlay S, Bellinger DC. 2007. Neuropsychological function in children with blood lead levels <10 microg/dL. Neurotoxicology. 2007 Nov;28(6):1170-7

[13] Thomas S, Arbuckle TE, Fisher M, Fraser WD, Ettinger A, King W. 2015. Metals exposure and risk of small-for-gestational age birth in a Canadian birth cohort: The MIREC study. Environ Res. 2015 Jul;140:430-9

[14] WHO - World Health Organization. 2015. Lead poisoning and health.

http://www.who.int/mediacentre/factsheets/fs379/en/ (visited 10/01/2016)

[15] Zailina H, Junidah R, Josephine Y, Jamal HH. Shamsul BS. 2008. The influence of low blood lead concentrations on the cognitive and physical development of primary school children in Malaysia. Asia Pac J Public Health. 2008;20(4):317-26

[16] Zailina H, Josephine Y, Shamsul BS, Jamal HH, Ariffin 0. 2002 McCarthy Score And Academic Performance Among Primary School Children In Kuala Lumpur, Malaysia. Malaysian J of Public Health Medicine, 2002;2(1):6-12.

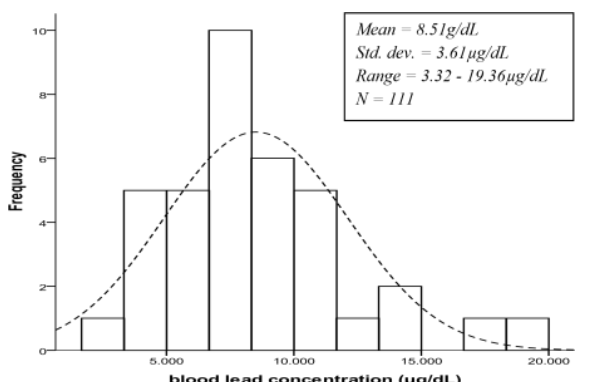

Figure 1: Distribution of blood lead concentration $(\mu \mathrm{g} / \mathrm{dL})$ among urban children

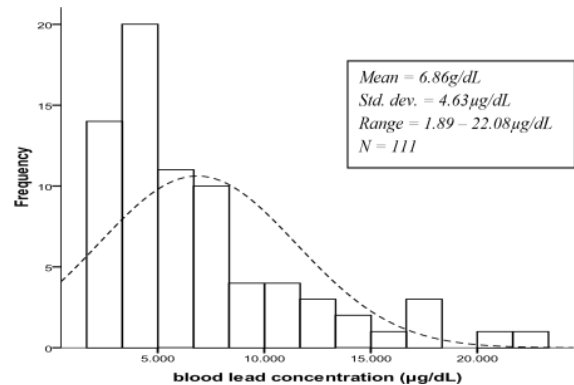

Figure 2: Distribution of blood lead concentration ( $\mu \mathrm{g} / \mathrm{dL})$ among rural children

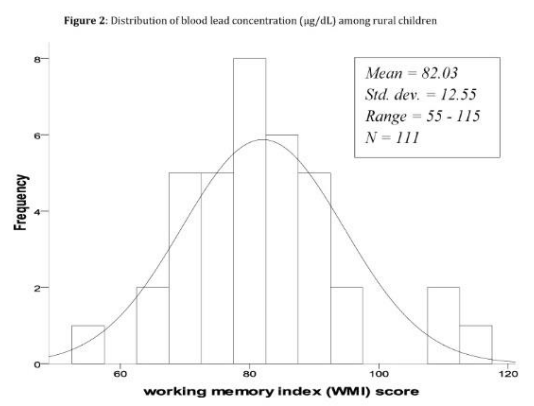

Figure 3: Distribution of working memory index (WMI) among urban children

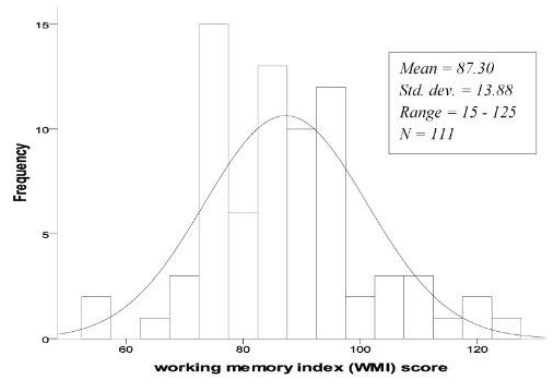

Figure 4: Distribution of working memory index (WMI) among rural children
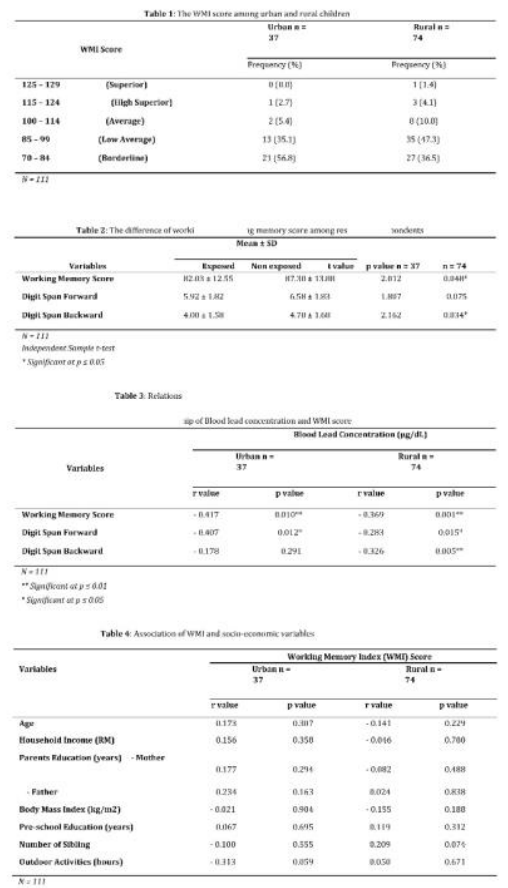